\title{
Effect of Season on UV Absorption Property of Costus Speciosus Leaves of Sikkim Himalayas
}

Tanaya Ghosh ${ }^{1}$, Prasenjit Mitra ${ }^{2}$, Prasanta Kumar Mitra ${ }^{3 *}$

${ }^{1}$ Department of Medical Biotechnology, Sikkim Manipal University, Sikkim Manipal Institute of Medical Sciences, Gangtok, Sikkim, India

${ }^{2}$ Department of Biochemistry, All India Institute of Medical Sciences (AIIMS), Basni Industrial Area, MIA 2nd Phase, Basni, Jodhpur, Rajasthan 342005, India

${ }^{3}$ Professor \& Head, Department of Medical Biotechnology, Sikkim Manipal University, Sikkim Manipal Institute of Medical Sciences, Gangtok, Sikkim, India

DOI: $10.36347 /$ sajp.2020.v09i01.004

| Received: 06.01.2020 | Accepted: 13.01.2020 | Published: 16.01.2020

*Corresponding author: Prasanta Kumar Mitra

Abstract

Original Research Article

Costus speciosus (C. speciosus), an edible leafy green, is known to possess a wide range of pharmacological properties. Recently we have shown UV absorption property of $C$. speciosus leaves of Sikkim Himalayas. Ethanol extract of $C$. speciosus leaves for 15 minutes at $40^{\circ} \mathrm{C}$ exerts maximum UV ray absorption property. It is known that pharmacological properties of medicinal plants are due to its secondary metabolite and amount of secondary metabolite varies with season. It is, therefore, thought worthwhile to study the seasonal effect on the UV absorption property of the $C$. speciosus leaves. Leaves of $C$. speciosus were collected in summer, winter, autumn and rainy seasons. Ethanol extracts of the leaves of different seasons were prepared separately. Extracts were allowed to absorb UV rays (wavelength range from $200 \mathrm{~nm}$ to $400 \mathrm{~nm}$ at $10 \mathrm{~nm}$ intervals) in a spectrophotometer to get absorption spectra. As polyphenols have relation with UV absorbing property amount of polyphenol in the leave extract was estimated. Results showed that ethanol extract of $C$. speciosus leaves of rainy season (June - August) had maximum UV absorbing property. Polyphenol content of the leaves was also high during rainy season. It is concluded that ethanol extract of $C$. speciosus leaves of rainy season may be used as anti solar agent in preparation of sun screen lotions.

Keywords: Costus speciosus leaves, UV absorbing property, seasonal effect, polyphenols, sun screen lotion.

Copyright @ 2020: This is an open-access article distributed under the terms of the Creative Commons Attribution license which permits unrestricted use, distribution, and reproduction in any medium for non-commercial use (NonCommercial, or CC-BY-NC) provided the original author and source are credited.

\section{INTRODUCTION}

Secondary metabolites of plants have no direct role in growth of the plant but are responsible to defend themselves against exogenous biotic / abiotic constraints. Different types of secondary metabolites present in plants are, terpenoids, phenols, alkaloids and sulphur containing compounds. These secondary metabolites are responsible for pharmacological activities of plants like anti diabetic, anti inflammatory, anti microbial, anti allergic, anti cancer, anti oxidant, anti gastric ulcer etc [1].

It is reported that amount of secondary metabolites present in plant varies with season. Influence of climate on secondary metabolites in medicinal plants was first studied by Fluck and Pharm [2]. Thereafter, many investigators have shown that accumulation of secondary metabolites in leaves, stem and roots of plants varies with season [3-7].
C. speciosus (family, Costaceae), found in tropical region of India along roadsides, streams and in wastelands, is an erect perennial herb [8]. It is edible leafy green. The plant is also found in moist tropical evergreen forests [9]. Known as keu in Bengali and Hindi the plant is used in traditional medicine as anthelmintic, expectorant purgative and stimulant. The plant is also used in the treatments of pneumonia, dropsy, jaundice, diarrhea, dysentery, dyspepsia, rheumatism, skin diseases, fever, bronchial asthma, urinary diseases, cough and cold, eye and ear infections as well as in snake bite cases [10].

C. speciosus showed many pharmacological properties like anti bacterial, anti fungal, antiinflammatory, anti diabetic, anti oxidant, antipyretic, antifertility, antihelminthic, hepatopretective, hypolipidemic, anti cancer etc. The plant also possess anticholinesterase and adaptogenic activities [11, 12]. 
Recently we found anti solar activity of $C$. speciosus leaves of Sikkim Himalayas. Ethanol extract of $C$. speciosus leaves for 15 minutes at $40^{\circ} \mathrm{C}$ exerts maximum UV ray absorption property. Aim of the present work was to study the seasonal effect on the UV absorption property of the $C$. speciosus leaves. As there is a positive correlation between amount of phenolic compounds in plant's leaf and its UV absorption property [13], effort was also made to estimate amount of phenolic compounds in the $C$. speciosus leaves of different seasons.

\section{MATERIAL AND METHODS Plant Material}

Leaves of $C$. speciosus were collected from the local market during autumn (September - November), winter (December - February), summer (March - May) and rainy season (June - August). Samples were authenticated by the taxonomist of the department of Botany of the University of North Bengal, Siliguri. A voucher specimen (No.SM-MB-011) was kept in the department of Medical Biotechnology, Sikkim Manipal Institute of Medical Sciences of Sikkim Manipal University, Gangtok, Sikkim, India for future reference.

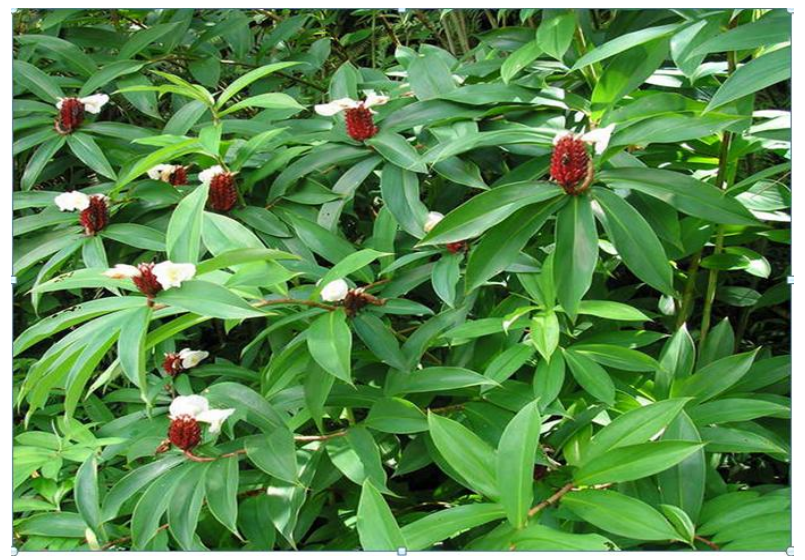

Fig-1: Costus speciosus leaves

\section{Test Drug}

Leaves of $C$. speciosus were washed thoroughly under tap followed by distilled water. Leaves were then shed dried and powered. The powder, used as test drug, was stored desiccated at $4{ }^{0} \mathrm{C}$ until further use.

\section{Solvent extraction}

Test drug (100g) of different seasons was extracted separately with $500 \mathrm{ml}$ of ethanol in soxhlet at $40^{\circ} \mathrm{C}$ for 15 minutes. Earlier we found that these conditions are needed to get maximum UV absorption property of $C$. speciosus leaves. The extract was filtered and the filtrate was evaporated to dryness in vacuo with rotary evaporator at $40-50{ }^{0} \mathrm{C}$. This was applied separately for all extracts. Brown masses obtained.

\section{Anti solar activity}

$10 \mathrm{mg}$ of this mass was dissolved in $100 \mathrm{ml}$ distilled water. The solution was processed in a spectrophotometer for UV ray absorption at the range of 200-400 nm.

\section{Determination of total phenols content}

Brown-yellow mass $(20 \mathrm{mg})$ obtained in extraction process was mixed with $100 \mathrm{ml}$ of distilled water. Solution was then filtered. Total phenols content of the filtrate was determined by the method of McDonald et al., [14]. Each experiment was done for five times and mean value calculated.

\section{Chemicals}

Chemicals required for the study were purchased from Merck, Germany and from Loba Chem. Lab, Himedia Lab, India.

\section{STATISTICAL ANALYSIS}

All experiments were conducted for three times. Data were analyzed statistically by SPSS 20 . The statistical significance between UV absorption spectra of different extracts was evaluated with Duncan's multiple range test (DMRT). $5 \%$ were considered to be statistically significant [15].

\section{RESULTS}

UV absorption spectra of ethanol extract of $C$. speciosus leaves leaves during autumn, winter, summer and rainy season is represented in Figure-2. Ethanol extract of the plant leaves of autumn absorbs maximum $\mathrm{UV}$ ray at $200 \mathrm{~nm}(0.79)$. UV ray absorptions by the same extract at $250 \mathrm{~nm}, 300 \mathrm{~nm}, 350 \mathrm{~nm}$ and $400 \mathrm{~nm}$ were $0.71,0.60,0.48$ and 0.40 respectively. Maximum UV absorption of ethanol extract of $C$. speciosus leaves of winter was found at $200 \mathrm{~nm}(0.85)$. At $250 \mathrm{~nm}, 300$ $\mathrm{nm}, 350 \mathrm{~nm}$ and $400 \mathrm{~nm}$ wave lengths UV absorption were, however, $0.80,0.67,0.53$ and 0.43 respectively. UV absorption spectra of ethanol extract of $C$. speciosus leaves of summer was found maximum at 200 $\mathrm{nm}$ (1.0). UV ray absorptions by the same extract at 250 $\mathrm{nm}, 300 \mathrm{~nm}, 350 \mathrm{~nm}$ and $400 \mathrm{~nm}$ were $0.89,0.72,0.59$ and 0.48 respectively. Maximum UV absorption of ethanol extract of $C$. speciosus leaves of rainy season was found at $200 \mathrm{~nm}(1.5)$. At $250 \mathrm{~nm}, 300 \mathrm{~nm}, 350 \mathrm{~nm}$ and $400 \mathrm{~nm}$ wave lengths UV absorption were 0.98 , $0.79,0.64$ and 0.55 respectively. Overall seasonal effect on UV radiation absorption by the ethanol extract of $C$. speciosus leaves at different wave lengths $(200-400$ $\mathrm{nm})$ is presented in Figure-3.

Seasonal effect on amount of phenolic compounds in C. speciosus leaves is shown in Figure-4. C. speciosus leaves collected during rainy season had $69.3 \mathrm{mg}$ phenolic compounds in $1 \mathrm{~g}$ dry wt of the leaves whereas $C$. speciosus leaves collected during autumn, winter and summer had $22.7 \mathrm{mg}, 31.5 \mathrm{mg}, 46.1 \mathrm{mg}$ of phenolic compounds per $\mathrm{g}$ dry wt of the leaves respectively. 


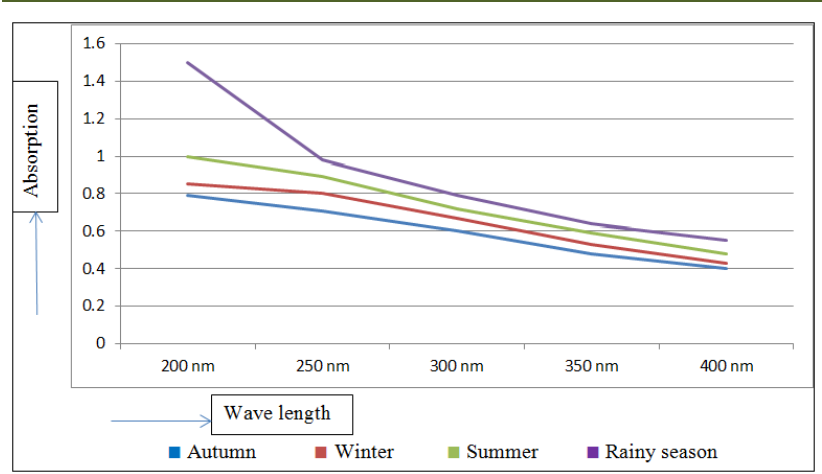

Fig-2: UV radiation absorptions by the ethanol extracts of $C$. speciosus leaves during autumn, winter, summer and rainy season.

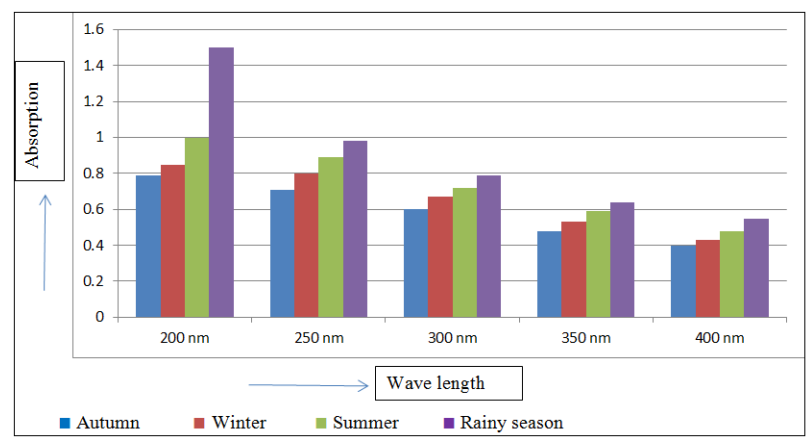

Fig-3: Effect of season on UV radiation absorption at different wave lengths by the ethanol extract of $C$. speciosus leaves

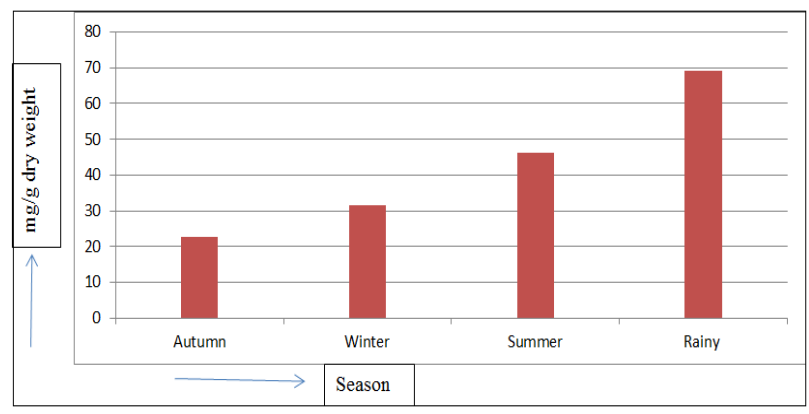

Fig-4: Amount of phenolic compounds in $C$. speciosus leaves: Effect of season

\section{DISCUSSION}

It is known that biological activity of a plant is mediated through secondary metabolite. It is also known that concentration of secondary metabolite varies with season. Celiktas et al., showed that antimicrobial activities of methanol extracts of Rosmarinus Officinalis was maximum during winter due to presence of high amount of essential oils in the plant [16]. That mineral nutrients and carbohydrates in walnut tree leaves were maximum in rainy season was the observation of Drossopoulos et al., [17]. Hussain et al. showed that chemical composition, antioxidant and antimicrobial activities of basil (Ocimum basilicum) essential oils depends on season [18]. Coli et al. investigated seasonal variation in activity of pear thrips (Thysanoptera: Thripidae) within stands of sugar maple and noted maximum activity in autumn [19]. We also reported that antibacterial activity of leaves of Murrya koenigii (linn.) spreng wettst. Varies with season [20].
In the present work it was observed that UV absorption (200-400 nm) property of $C$. speciosus leaves was maximum in rainy season followed by summer, winter and autumn (Figure-3).

Ali. et al showed that there is a positive correlation between amount of phenolic compounds in plant's leaf and its UV absorption property [13]. We also reported that UV absorption property of Murrya koenigii (Linn) Spreng Wettst leaves was related with its polyphenol content [21]. More polyphenol content of the plant leaves absorbed more ultraviolet radiation. In the present study polyphenol content of of C. speciosus leaves of different seasons was estimated. Results showed that amount of polyphenol in the plant leaves was maximum in rainy season when the leaves had maximum UV ray absorption capacity (Figure-4). The present finding thus supports the earlier observations.

In human body ultraviolet radiation is responsible for cutaneous synthesis of vitamin - D. Vitamin - D is involved in formation of bones in humans. People who have low vitamin $-\mathrm{D}$ in body suffer from thinning or brittle bones, osteoporosis, anxiety or depression. But, at the same time ultraviolet radiation is bad for human body also. It has been reported that excess ultra violet ray can cause many detrimental effects including skin cancer and change in distribution and function of white blood cells thereby suppressing effect on the immune system in humans [22].

Under the circumstances there is continuous search for the sources which can absorb UV radiation from the environment thereby protecting humans. Medicinal plants were taken as the source and it was found out that many medicinal plants have ultra violet absorption property [23, 24].

In the present work we found UV ray absorption property of $C$. speciosus leaves of Sikkim Himalayas. Compound responsible for this property now needs isolation from the plant leaves. Presently work is going on in this direction in our laboratory.

\section{CONCLUSION}

In this study we observed that ethanol extract of $C$. speciosus leaves of rainy season had maximum UV absorbing property. From this plant leaves active compound may be isolated which, in turn, can be used in preparation of sun screen lotions in future.

\section{ACKNOWLEDGEMENTS}

Cooperation of taxonomists of the department of Botany, University of North Bengal, Siliguri, Dist. Darjeeling, West Bengal in identification of $C$. speciosus leaves is gratefully acknowledged.

\section{Conflict of interest: Nil}




\section{REFERENCES}

1. Guerriero G, Berni R, Muñoz-Sanchez J, Apone F, Abdel-Salam E, Qahtan A, Alatar A, Cantini C, Cai G, Hausman JF, Siddiqui K. Production of plant secondary metabolites: Examples, tips and suggestions for biotechnologists. Genes. 2018 Jun;9(6):309.

2. Fluck H, Pharm M. The influence of climate on the active principles in medicinal plants. J. Pharm. Pharmacol. 1955; 7: 361-383.

3. Arambewela LSR, Ratnayake CK. Vasicine contents and their seasonal variation in Adhatoda vvasica. Fitoterapia. 1988;59(2):151-153.

4. Feeny P. Seasonal changes in oak leaf tannins and nutrients as a cause of spring feeding by winter moth caterpillars. Ecology. 1970;51:565-581.

5. Gupta PL. Variation in morphological characters and active principle constituents of Eclipta prostrata Linn. under different seasonal and soil conditions. JRIM, 1977; 12(1): 80-84.

6. Mauffette Y, Oechel WC. Seasonal variation in leaf chemistry of the coast liveoak Quercus agrifolia and implications for the California oak moth. Phryganidia californica Oecologia. 1989;79:439-445.

7. Schultz JC, Nothnagle PJ, Baldwin IT. Seasonal and individual variation in leaf quality of two northern hardwoods tree species. American Journal of Botan. 1982; 69:753-759.

8. Gupta AK, Tondon N, Sharma M. Quality Standards of Indian Medicinal Plants, Medicinal Plants Unit, Published by Indian Council of Medical Research. 2008; 7:48.

9. Gupta RK. Medicinal and Aromatic Plants, CBS Publishers and Distributors, New Delhi. 2010; 499.

10. Srivastava S, Singh P, Mishra G, Jha KK, Khosa RL. Costus speciosus (Keukand): A review. Der Pharmacia Sinica. 2011; 2(1):118-128.

11. Bhattacharya SK, Parik AK, Debnath, PK, Pandey, VB, Neogy, NC. Anticholinesterase activity activity of Costus speciosus alkaloids. Indian Journal Pharmacol. 1972; 4:178-178.

12. El-Far AH, Shaheen HM, Alsenosy AW, El-Sayed YS, Al Jaouni SK, Mousa SA. Costus speciosus: Traditional Uses, Phytochemistry, and Therapeutic Potentials. Pharmacognosy Reviews. 2018 Jan 1;12(23):120-127.

13. Ebrahimzadeh MA, Enayatifard R, Khalili M, Ghaffarloo M, Saeedi M, Charati JY. Correlation between sun protection factor and antioxidant activity, phenol and flavonoid contents of some medicinal plants. Iranian journal of pharmaceutical research: IJPR. 2014;13(3):1041-1047.

14. McDonald S, Prenzler PD, Antolovich M, Robards K. Phenolic content and antioxidant activity of olive extracts. Food chemistry. 2001 Apr 1;73(1):73-84.

15. Bliss CI. Statistics in biology, Statistical methods for research in the natural Sciences, Vol. 1, McGraw Hill Book Company. NY. 1967: 558.

16. Celiktas OY, Kocabas EEH, Bedir E, Sukan FV, Ozek T, Baser KHC. Antimicrobial activities of methanol extracts and essential oils of Rosmarinus officinalis depending on location and seasonal variations. Food Chem. 2007;100:553-559.

17. Drossopoulos B, Kouchaji GG, Bouranis DL. Seasonal dynamics of mineral nutrients and carbohydrates by walnut tree leaves. Journal Plant Nutr. 1996;19:493-516.

18. Hussain AI, Anwar F, Sherazi STH, Przybylski R. Chemical composition, antioxidant and antimicrobial activities of basil (Ocimum basilicum) essential oils depends on seasonal variations. Food Chem. 2008;108:986-995.

19. Coli WM, Hollingsworth CS, Hosmer TA. Seasonal and vertical variation in activity of pear thrips (Thysanoptera: Thripidae) within stands of sugar maple. Canadian Journal of Research. 1997;27:667-673.

20. Mitra P, Ghosh T, Mitra PK. Seasonal variation in antibacterial activity of leaves of Murrya koenigi (linn.) spreng wettst. European J Biomedical and Pharmaceutical Sciences. 2019:5(4), 782-786.

21. Mitra P, Ghosh T, Mitra PK. UV Absorption Property of Murrya koenigii (Linn) Spreng Wettst Leaves: Effect of Extraction Solvents. Scholars Academic Journal of Pharmacy. 2019;8(4):129134.

22. Gharge VG, Yadav A. Study of Methanolic Extract of Leaves Calotropis gigantean (L.) As an Anti- Solar. Adv Complement Alt Med. 2018;1(4):1-3.

23. Gupta D. Absorbing Properties of Some Plant Derived Extracts. Research Journal of Chemical and Environmental Sciences. 2013;1(2):34-36.

24. Gupta V. Environment friendly antibacterial and uv protective finish on cotton using $\mathrm{S}$. cumini (1.) leaves extract. International Journal of Textile and Fashion Technology. 2017;7(1):53-62. 